\title{
Effects of Arterial Carbon Dioxide Tension on the Newborn Lamb's Cardiovascular Responses to Rapid Hemorrhage
}

\author{
AUGUSTO SOLA, ALAN R. SPITZER, FREDERICK C. MORIN III, MUREEN A. SCHLUETER, AND \\ RODERIC H. PHIBBS ${ }^{(39)}$ \\ Department of Pediatrics and the Cardiovascular Research Institute, University of California-San Francisco, \\ California, USA
}

\begin{abstract}
Summary
Nineteen newborn lambs, spontaneously breathing room air, were hemorrhaged of $50 \%$ of their measured blood volume over a 30-min period. They were then observed for the following $90 \mathrm{~min}$. No fluid or blood was reinfused during the study. Eight of the 19 lambs survived beyond the study period, the other 11 died at the end of the hemorrhage or during the recovery period. All lambs became hypotensive and bradycardic during the hemorrhage. All became tachycardic after the hemorrhage. Blood pressure of the survivors returned towards baseline levels whereas it continued to fall in the non-survivors. All animals became anemic, acidotic, and hypocarbic but remained normoxemic.

Myocardial blood flow fell to approximately $50 \%$ of baseline levels in both survivors and non-survivors during, and at the end of the hemorrhage. It returned to near baseline levels in the survivors by $90 \mathrm{~min}$ posthemorrhage. Cerebral blood flow remained at baseline levels during the hemorrhage in the survivors but cerebral oxygen delivery decreased. Flow rose $10 \%$ above baseline levels 90 min after hemorrhage but oxygen delivery remained low. In the non-survivors, cerebral blood flow fell to $60 \%$ of baseline and cerebral oxygen delivery was $50 \%$ of baseline by the end of the hemorrhage.

A group of five lambs was hemorrhaged and studied in the same fashion as the 19, except that they breathed $4.5 \% \mathrm{CO}_{2}$ beginning $15 \mathrm{~min}$ before the hemorrhage, during the hemorrhage and $90 \mathrm{~min}$ recovery period. Four of these five survived the study period. They remained normocarbic and became more acidotic than the animals that breathed room air. Blood pressure and heart rate fell during hemorrhage but these decreases were less than in either group of room air breathing animals. During recovery they became tachycardic and blood pressure returned to baseline levels. Myocardial blood flow increased $20 \%$ above baseline by the end of hemorrhage and $40 \%$ above baseline by $90 \mathrm{~min}$ posthemorrhage. Cerebral blood flow increased $40 \%$ above baseline during the hemorrhage and remained at that level at the end of hemorrhage and $90 \mathrm{~min}$ afterwards. The increase in brain blood flow was sufficient to maintain oxygen delivery to the brain at baseline levels throughout the experiment.
\end{abstract}

\section{Speculation}

We speculate that the normal response for the normocarbic lambs is to increase cerebral and myocardial blood flow in response to anemia and hypotension. Spontaneous hyperventilation with hypocarbia tends to interfere with this response both in the brain and in the myocardium. The effect of hypocarbia is greater in the myocardium. The net result is a decrease in oxygen delivery to these tissues. If the same responses were to occur in the human infant it might be important to maintain normocarbia during resuscitation of infants suffering from hemorrhagic shock.
The newborn infant is susceptible to sudden, massive hemorrhage because of its vulnerability to major blood loss through the umbilical-placental circulation at birth $(7,9,22)$. Hypovolemia with blood loss of as much as $50 \%$ of the normal blood volume has been documented by clinical studies $(1,4,9,28)$; however, there have been only a few studies of the adaptive responses of newborn animals to sudden massive hemorrhage and none of these studies have examined the changes in blood flow to the major organs due to hemorrhage.

We have studied the responses of unanesthetized lambs to rapid hemorrhage without any volume replacement. Because the lamb hyperventilates and becomes hypocarbic in response to hemorrhage, we have also examined their responses to hemorrhage when the hypocarbia was prevented by having them breathe $4.5 \% \mathrm{CO}_{2}$ and $21 \% \mathrm{O}_{2}$.

\section{MATERIALS AND METHODS}

Twenty-four newborn lambs of mixed Western strain were studied 2-10 days after spontaneous delivery at term gestation. Their weight ranged between $3.5-8.2 \mathrm{~kg}$. They were kept with their ewes until the time of the study. All procedures and the subsequent studies were done with the animals blindfolded, gently restrained, lying on their sides and breathing spontaneously. Local anesthetics were used for inserting intravascular catheters. No general anesthetics were used. Body temperature was measured with a rectal thermometer.

With sterile technique and under local infiltration anesthesia with $1 \%$ xylocaine, we placed an 8 French polyvinyl catheter in the lower abdominal aorta via a hind limb artery, and a 4 French catheter into either the left atrium via a left hind limb vein or the left ventricle via the left brachial artery. The positions of these catheter tips were confirmed by postmortem examination. The right brachial artery was also cannulated.

Red blood cell mass (RCM) was measured using CsCl-labeled red blood cells and fluorescent excitation analysis (29). In order to calculate total body hematocrit $\left(\mathrm{Hct}_{\mathrm{TB}}\right)$ from the measured venous blood hematocrit (Hct), we used an F-cell ratio of 0.71 , which we had previously determined was the average for this age and breed of animal from combined measurements of RCM, Hct, and plasma volume $\left(\right.$ Hct $_{\mathrm{TB}}=\mathrm{Hct} \times \mathrm{F}$-cell ratio). We then used the measured $\mathrm{RCM}$ to calculate total blood volume (TBV) as follows: TBV $=$ RCM/Hct TB.

The Hct was measured by collecting venous blood in heparinized microcapillary tubes and centrifuging them for $3 \mathrm{~min}$ at 3000 rpm. Plasma total proteins were measured by the refractometric method of Wolf et al. (37) (TS meter, American Optical Corp., Buffalo, NY). Arterial blood gases and $\mathrm{pH}$ were measured using a Radiometer blood gas analyzer and hemoglobin and oxygen saturation, using a Radiometer OSM2 Hemoximeter (Radiometer Copenhagen). Arterial blood pressure and heart rate were contin- 
uously recorded from the brachial artery catheter, with a blood pressure transducer and polygraph recorder. Arterial blood oxygen content was calculated from hemoglobin concentration and oxygen saturation (23).

Organ blood flows (Q) were determined in animals with left atrial or left ventricular catheters by injecting carbonized radioactive microspheres, 15 microns in diameter, labeled with one of several $\gamma$ isotopes $(\mathrm{Sr}, \mathrm{Ce}, \mathrm{I}, \mathrm{Nb}$, and $\mathrm{Sc}$ ) through these catheters. Blood specimens for lower and upper body reference samples were withdrawn from the aortic and brachial artery catheters at a constant rate with a Harvard pump. At the end of the experiments, the organs from the dead lambs were removed, ashed, and counted separately according to the method of Heymann et al. (16). Organ blood flow $(\mathrm{Q})$ was calculated by relating the count for each organ to the count in the reference samples obtained at a known flow rate $(Q=$ reference flow $\times$ count in organ/reference count $)$. The radioactivity of the lungs was checked to be sure there was no intracardiac left to right shunting during the injections.

Red cell mass was measured either 3 or $4 \mathrm{~h}$ before the hemorrhage or the day before. In the latter case, two of the above catheters were placed the day before the hemorrhage study.

Nineteen lambs breathed room air and the protocol consisted of three periods during which heart rate and blood pressure were continuously recorded. Blood gas tensions, $\mathrm{pH}$, Hct, and total proteins were measured in all 19 lambs; organ blood flow was measured in 11 (four survivors and seven non-survivors). These were the last 11 consecutive animals studied in the room air breathing group.

Period (1), Baseline period lasted 50-60 min. At the end of this period arterial blood gases, $\mathrm{pH}$, Hct, total proteins, and organ flows were determined. Period 2 followed immediately. Period (2), Hemorrhage lasted $30 \mathrm{~min}$. During this time, approximately $50 \%$ of the measured TBV was allowed to flow through the aortic catheter into a heparinized graduated cylinder. At approximately $20 \mathrm{~min}$, when two-thirds of the planned volume of hemorrhage was removed, arterial blood gases, $\mathrm{pH}, \mathrm{Hct}$, total proteins, and organ flows were measured. These measurements were repeated at the end of hemorrhage. We measured the total volume of blood removed and the hematocrit of the blood in the collection cylinder. In six animals (three survivors and three non-survivors), we remeasured RCM at the end of the hemorrhage and calculated TBV assuming that the F-cell ratio was still 0.71 .

Period (3), Recovery (posthemorrhage). All the lambs were observed for $90 \mathrm{~min}$ without volume reinfusion. We measured arterial blood gases, $\mathrm{pH}, \mathrm{Hct}$, and total proteins at 20,40, and $90 \mathrm{~min}$. Organ flows were also measured at $90 \mathrm{~min}$ posthemorrhage.

After these periods, the surviving lambs were killed with an intravenous injection of pentobarbital. In the 11 lambs injected with microspheres, the brain, heart, kidneys, adrenals and samples of upper and lower limb and skeletal muscle were removed and processed for $\gamma$ counting (16).

Another five lambs were studied with the same protocol just described, except that after the baseline measurements breathing room air, the animals were given $4.5 \% \mathrm{CO}_{2}$ with $21 \% \mathrm{O}_{2}$ to breathe. The gas mixture was delivered into a plastic bag, which was placed over the lambs' head and fitted loosely around the neck to avoid compressing neck veins. The gas in the bag was analyzed frequently and its $\mathrm{CO}_{2}$ concentration maintained constant. High flow rates were used in order to avoid rebreathing. After $15 \mathrm{~min}$ of breathing $4.5 \% \mathrm{CO}_{2}$, just before starting the hemorrhage, we determined arterial blood gases, $\mathrm{pH}$, Hct, total proteins, and organ flows. The five lambs were then bled in the standard fashion and measurements were made at the same times during the hemorrhage and recovery periods. They continued to breathe the $4.5 \% \mathrm{CO}_{2}, 21 \% \mathrm{O}_{2}$ mixture throughout the hemorrhage and recovery period.

We analyzed the data by classifying the animals into three groups: room-air breathing survivors, room-air breathing non- survivors and $\mathrm{CO}_{2}$-breathing animals. We examined the changes in each variable within each group by comparing the baseline values with each of the subsequent values of that variable. The statistical significance of these changes was evaluated by paired $t$ tests using the Bonferroni correction for multiple $t$ tests (25). We also examined the differences between groups for each variable at each observation point during the study. The significance of these inter-group differences was evaluated by the Duncan multiple range test (25). In all evaluations we accepted a 0.05 level of confidence as a significant results.

\section{RESULTS}

Eight of the 19 lambs that breathed room air survived beyond the $90 \mathrm{~min}$ posthemorrhage observation period. Seven of the 11 that did not survive, died during the first $20 \mathrm{~min}$ of the posthemorrhage observation period. The other four died after $40 \mathrm{~min}$ but before 90 min posthemorrhage.

$T B V$, volume of hemorrhage and posthemorrhage $T B V$ and $R C M$. Table 1 shows the total blood volumes and the volumes of hemorrhage expressed as \% of the total blood volume and as $\mathrm{ml}$ per $\mathrm{kg}$ bodyweight $(\mathrm{ml} / \mathrm{kg})$. Although the differences between the groups were small for all variables, some differences were significant when analyzed by the Duncan multiple range test (25). Total blood volume was larger in the room-air non-survivors than in the survivors, but the total blood volume of the $\mathrm{CO}_{2}$ group was not different from either room-air group. The $\mathrm{ml} / \mathrm{kg}$ hemorrhaged was larger in the non-survivors than that in either the survivors or the $\mathrm{CO}_{2}$ group. The percentage of blood volume hemorrhaged was also slightly but significantly greater in the non-survivors than survivors. The percentage hemorrhaged in the $\mathrm{CO}_{2}$ group was not significantly different from either of the room-air groups.

The sum of the posthemorrhage volume and the volume of shed blood of all six animals in which we remeasured blood volume at the end of the hemorrhage was always larger than the initial blood volume measured. This indicated an addition to the blood volume during the course of the hemorrhage. The volume added averaged $15.5 \mathrm{ml} / \mathrm{kg}$ or $14.5 \%$ (S.D. $8.3 \%$ ) of the initial blood volume. If part of this increase was due to the addition of red cells to the circulation, this could be detected by comparing the RCM posthemorrhage plus the RCM of the shed blood to the baseline RCM. We calculated the RCM of the shed blood from the hematocrit of the mixed blood in the collection cylinder and the total volume of blood shed. In each of the six animals we calculated the ratio.

$$
\frac{(\mathrm{RCM} \text {-shed + RCM posthemorrhage })-(\mathrm{RCM} \text { baseline })}{\mathrm{RCM} \text { baseline }}
$$

to express such an increase as a \% of the prehemorrhage RCM. In the six, the average value for this ratio was not significantly different from $0,(\mathrm{X}=-2.8 \%$, S.E. $=4.4 \%)$ suggesting that there was no sequestered pool of red cells added to the circulation during the hemorrhage. This further suggests that the increase in

Table 1. Total blood volume (TBV) before hemorrhage and blood volume removed during hemorrhage in the three groups of lambs ${ }^{1}$

\begin{tabular}{|c|c|c|c|}
\hline & \multicolumn{2}{|c|}{ Room air } & \multirow{2}{*}{$\begin{array}{c}\mathrm{CO}_{2} \\
(n=5)\end{array}$} \\
\hline & $\begin{array}{c}\text { Survivor } \\
(n=8)\end{array}$ & $\begin{array}{c}\text { Nonsurvivor } \\
(n=11)\end{array}$ & \\
\hline TBV (ml/kg) & $98.2 \pm 10.1^{2}$ & $106.4 \pm 8.8^{2}$ & $95.4 \pm 8.2$ \\
\hline $\begin{array}{l}\text { BV removed } \\
\text { (\% TBV) }\end{array}$ & $46.7 \pm 4.7^{2}$ & $50.6 \pm 2.8^{2}$ & $48.2 \pm 1.8$ \\
\hline $\begin{array}{l}\text { BV removed } \\
(\mathrm{ml} / \mathrm{kg})\end{array}$ & $46.0 \pm 5.4^{2}$ & $53.6 \pm 4.1^{2}$ & $45.9 \pm 5.8$ \\
\hline
\end{tabular}

${ }^{1}$ Values are mean \pm S.E.

${ }^{2}$ Significant difference between these groups. 
Table 2. Heart rate, blood pressure, blood gas tensions, hematocrit, and total proteins during hemorrhage

\begin{tabular}{|c|c|c|c|c|c|c|c|}
\hline & \multirow{2}{*}{ Baseline } & \multirow{2}{*}{ After $\mathrm{CO}_{2}$} & \multicolumn{2}{|c|}{ Hemorrhage } & \multicolumn{3}{|c|}{ After hemorrhage } \\
\hline & & & $2 / 3$ & End & $20 \mathrm{~min}$ & $40 \mathrm{~min}$ & $90 \mathrm{~min}$ \\
\hline \multicolumn{8}{|c|}{ Mean blood pressure } \\
\hline $\mathrm{S}$ & $76.4 \pm 21.4$ & & $44.6 \pm 21.3 \downarrow$ & $24.3 \pm 10.0 \downarrow B$ & $51.8 \pm 15.8$ & $56.1 \pm 14.5 \mathrm{~B}$ & $58.7 \pm 14.5$ \\
\hline NS & $84.2 \pm 13.0$ & & $34.2 \pm 11.36 \downarrow \mathrm{A}$ & $22.66 \pm 10.34 \downarrow \mathrm{B}$ & $32.5 \pm 10.6$ & $26.0 \pm 11.5 \downarrow \mathrm{A}$ & \\
\hline $\mathrm{CO}_{2}$ & $83.6 \pm 9.3$ & $82.4 \pm 7.9$ & $58.7 \pm 4.6 \downarrow \mathrm{B}$ & $46.4 \pm 9.1 \downarrow \mathrm{A}$ & $49.6 \pm 24.5$ & $67.0 \pm 20.7 \mathrm{~B}$ & $64.5 \pm 19.2$ \\
\hline \multicolumn{8}{|c|}{ Heart rate } \\
\hline $\mathrm{S}$ & $214.0 \pm 37.3$ & & $176.0 \pm 56.0$ & $154.0 \pm 32.0 \downarrow \mathrm{A}$ & $240.14 \pm 54.03$ & $247.14 \pm 53.45$ & $255.71 \pm 44.94 \uparrow$ \\
\hline NS & $205.0 \pm 31.0$ & & $143.0 \pm 31.0 \downarrow \mathrm{A}$ & $190.0 \pm 44.0$ & $228.0 \pm 86.0$ & $226.0 \pm 84.0$ & \\
\hline $\mathrm{CO}_{2}$ & $232.0 \pm 22.0$ & $248.0 \pm 22.0$ & $220.0 \pm 45.0 \mathrm{~B}$ & $207.0 \pm 25.0 \mathrm{~B}$ & $219.4 \pm 76.2$ & $271.2 \pm 21.4$ & $272.0 \pm 19.4$ \\
\hline \multicolumn{8}{|l|}{$\mathrm{PaO}_{2}$} \\
\hline $\mathrm{S}$ & $80.9 \pm 14.4$ & & $88.0 \pm 25.7$ & $94.4 \pm 25.4 \uparrow$ & $106.4 \pm 15.5 \uparrow$ & $101.6 \pm 23.8 \uparrow$ & $100.0 \pm 27.2$ \\
\hline NS & $78.1 \pm 17.3$ & & $78.5 \pm 25.6$ & $69.5 \pm 29.8 \mathrm{~A}$ & $88.8 \pm 24.4 \mathrm{~A}$ & $80.5 \pm 44.5$ & \\
\hline $\mathrm{CO}_{2}$ & $89.0 \pm 8.1$ & $103.4 \pm 10.9$ & $114.8 \pm 11.12 \uparrow$ & $116.4 \pm 14.6 \uparrow \mathrm{B}$ & $112.8 \pm 7.9 \uparrow \mathrm{B}$ & $116.5 \pm 9.7 \uparrow$ & $115.5 \pm 14.4 \uparrow$ \\
\hline \multicolumn{8}{|l|}{$\mathrm{PaCO}_{2}$} \\
\hline $\mathrm{S}$ & $33.7 \pm 3.8$ & & $28.7 \pm 2.8 \downarrow$ & $25.7 \pm 2.9 \downarrow \mathrm{A}$ & $25.1 \pm 4.0 \downarrow B$ & $25.2 \pm 4.7 \downarrow \mathrm{A}$ & $19.3 \pm 3.7 \downarrow \mathrm{A}$ \\
\hline NS & $37.4 \pm 5.8$ & & $31.4 \pm 6.7 \downarrow$ & $20.4 \pm 8.3 \downarrow B$ & $22.8 \pm 5.1 \downarrow \mathrm{B}$ & $18.8 \pm 4.0 \mathrm{~B}$ & \\
\hline $\mathrm{CO}_{2}$ & $33.0 \pm 2.0$ & $40.6 \pm 2.2 \uparrow$ & $35.6 \pm 3.6$ & $33.5 \pm 2.6 \mathrm{C}$ & $37.4 \pm 4.5 \mathrm{~A}$ & $32.21 \pm 2.8 \mathrm{C}$ & $34.2 \pm 2.1 \mathrm{~B}$ \\
\hline \multicolumn{8}{|l|}{$\mathrm{pH}$} \\
\hline $\mathrm{S}$ & $7.40 \pm 0.03$ & & $7.33 \pm 0.08 \mathrm{~B}$ & $7.25 \pm 0.08 \downarrow$ & $7.19 \pm 0.10 \downarrow$ & $7.17 \pm 0.13 \downarrow$ & $7.13 \pm 0.22$ \\
\hline NS & $7.40 \pm 0.04$ & & $7.34 \pm 0.07 \downarrow \mathrm{B}$ & $7.30 \pm 0.18$ & $7.14 \pm 0.16$ & $6.98 \pm 0.12 \downarrow$ & \\
\hline $\mathrm{CO}_{2}$ & $7.37 \pm 0.01$ & $7.31 \pm 0.03$ & $7.23 \pm 0.08 \mathrm{~A}$ & $7.18 \pm 0.12$ & $7.04 \pm 0.26$ & $7.12 \pm 0.12$ & $7.13 \pm 0.15$ \\
\hline \multicolumn{8}{|c|}{ Hematocrit } \\
\hline $\mathrm{S}$ & $32.0 \pm 4.3$ & & $27.0 \pm 5.0 \downarrow$ & $20.9 \pm 3.2 \downarrow$ & $21.0 \pm 2.9 \downarrow$ & $22.0 \pm 3.9 \downarrow$ & $20.4 \pm 1.4 \downarrow$ \\
\hline NS & $30.1 \pm 4.3$ & & $24.45 \pm 4.68 \downarrow$ & $22.22 \pm 4.08 \downarrow$ & $19.83 \pm 4.02 \downarrow$ & $22.3 \pm 2.08$ & \\
\hline $\mathrm{CO}_{2}$ & $29.6 \pm 4.1$ & $29.5 \pm 4.5$ & $23.2 \pm 2.0 \downarrow$ & $21.50 \pm 4.5 \downarrow$ & $20.0 \pm 5.4 \downarrow$ & $22.0 \pm 2.3 \downarrow$ & $22.5 \pm 1.2 \downarrow$ \\
\hline \multicolumn{8}{|c|}{ Total protein } \\
\hline $\mathrm{S}$ & $5.9 \pm 1.1 B$ & & $5.3 \pm 0.8$ & $4.8 \pm 0.9 \downarrow$ & $5.1 \pm 0.9 \downarrow$ & $5.2 \pm 0.6$ & $5.1 \pm 0.9 \downarrow \mathrm{A}$ \\
\hline NS & $5.6 \pm 0.8 \mathrm{~B}$ & & $5.0 \pm 0.7 \downarrow$ & $4.8 \pm 0.6 \downarrow$ & & & \\
\hline $\mathrm{CO}_{2}$ & $7.0 \pm 0.4 \mathrm{~A}$ & $6.90 \pm 0.4$ & $5.8 \pm 0.6 \downarrow$ & $5.6 \pm 0.5 \downarrow$ & $5.7 \pm 0.4 \downarrow$ & $5.8 \pm 0.2 \downarrow$ & $6.10 \pm 0.4 \downarrow \mathrm{B}$ \\
\hline
\end{tabular}

' Values are mean \pm S.D.

${ }^{2}$ Definitions: $\uparrow$, significantly higher than baseline value in that group $(P<0.05)$; $\downarrow$, significantly lower than baseline value in this group $(P<$ 0.05 ); A, B or A, B, B: group A is significantly different from group B (or from both other groups, B, B) at that point in the study $(P<0.05$ ); A, $\mathrm{B}, \mathrm{C}$ : each group is significantly different from the other two at that point in the study $(P<0.05)$; $\mathrm{S}$, room air breathing survivors; NS, room air breathing non-survivors; and $\mathrm{CO}_{2}, \mathrm{CO}_{2}$ breathing animals.

blood volume during the hemorrhage was due only to hemodilution, which is consistent with the decrease in hematocrit and total proteins.

Heart rate and mean blood pressure. Table 2 shows the blood pressure and heart rate changes. All three groups of lambs became hypotensive and bradycardic during the hemorrhage. Thereafter, heart rate rose in all three groups; blood pressure rose in the roomair aurvivors and the $\mathrm{CO}_{2}$ group, but continued to fall in the room-air non-survivors. Bradycardia was present at half the hemorrhage in the room-air breathing groups. It was greatest in the non-survivors and the nadir occurred at two-thirds hemorrhage. In the survivors, the nadir occurred at end-hemorrhage. In the $\mathrm{CO}_{2}$ group, heart rate rose slightly after the onset of $\mathrm{CO}_{2}$ breathing. It then decreased during hemorrhage but was higher than in the room-air groups and was never significantly below baseline. Blood pressure was consistently higher in the $\mathrm{CO}_{2}$ group during the hemorrhage but similar to the room-air survivors during the recovery period.

Arterial blood gas tensions and $\mathrm{pH}$. Table 2 shows the changes in $\mathrm{pH}, \mathrm{PaCO}_{2}$ and $\mathrm{PaO}_{2}$. All lambs became acidemic during the experiment. In the $\mathrm{CO}_{2}$ group, the $\mathrm{pH}$ tended to be lower than in the room-air survivors but this difference was only significant at two-thirds hemorrhage. By 90 min posthemorrhage, the $\mathrm{CO}_{2}$ group was identical to the room-air survivors.

All lambs in room air became progressively more hypocarbic during the experiment. By $40 \mathrm{~min}$ posthemorrhage, non-survivors were significantly more hypocarbic than the survivors. All lambs in the $\mathrm{CO}_{2}$ group had a small, but significant, rise in $\mathrm{PaCO}_{2}$ after $15 \mathrm{~min}$ of breathing $4.5 \% \mathrm{CO}_{2}$. This increased averaged 7.6 torr. In the $\mathrm{CO}_{2}$ group there was no hypocarbia during and after the hemorrhage; the $\mathrm{pCO}_{2}$ remained very close to baseline values from the start of the hemorrhage and was significantly higher than the lambs in room-air. In all three groups, the acidosis during and after hemorrhage was metabolic. By the end of the hemorrhage, the room-air non-survivors had a slightly greater base deficit than the room-air survivors ( $\mathrm{mEq} /$ liter -17.7 versus $-14.2 \mathrm{mEq} / \mathrm{liter}$ ).

$\mathrm{PaO}_{2}$ rose in the room-air survivors and $\mathrm{CO}_{2}$-breathing animals during the hemorrhage and recovery period. $\mathrm{PaO}_{2}$ did not change in the room-air non-survivors and by the end of the hemorrhage and $20 \mathrm{~min}$ posthemorrhage was significantly lower than in the $\mathrm{CO}_{2}$ group. At 20 and $40 \mathrm{~min}$ posthemorrhage there were extreme variations in $\mathrm{PaO}_{2}$ in the non-survivors so that some animals were quite hypoxemic.

Hematocrit and total proteins. Table 2 shows the changes in Hct and total proteins. The Hct fell similarly in all lambs. It was 65 $73 \%$ of baseline values at the end of hemorrhage and remained in this range during the recovery period. The baseline total proteins were higher in the $\mathrm{CO}_{2}$ group compared to the groups in room air; however, the relative fall in total proteins was similar in all three groups and there were no differences between groups until 90 min posthemorrhage when they were lower in the room-air survivors than in the $\mathrm{CO}_{2}$-breathing lambs. Total proteins fell proportionately less than Hct, ranging from $81-87 \%$ of baseline values at the end of the hemorrhage and $86-88 \%$ of baseline 90 min posthem- 
Table 3. Organ blood flow in $\mathrm{ml} / \mathrm{min} / 100 \mathrm{~g}$ of tissue during and after hemorrhage $\mathrm{e}^{1,2}$

\begin{tabular}{|c|c|c|c|c|c|c|}
\hline & Baseline & Post $\mathrm{CO}_{2}$ & & \multicolumn{2}{|c|}{ Hemorrhage } & $90 \mathrm{~min}$ posthemorrhage \\
\hline \multicolumn{7}{|l|}{ Brain } \\
\hline NS & $76.4 \pm 7.6$ & & & $77.9 \pm 7.6$ & $47.3 \pm 18.6 \downarrow \mathrm{A}$ & \\
\hline $\mathrm{CO}_{2}$ & $72.2 \pm 6.2$ & $81.5 \pm 7.9$ & & $91.9 \pm 18.6$ & $101.4 \pm 6.60 \uparrow \mathrm{B}$ & $96.1 \pm 4.2 \uparrow$ \\
\hline NS & $188.4 \pm 56.9$ & & & $81.6 \pm 29.6 \downarrow \mathrm{B}$ & $81.0 \pm 31.2 \downarrow \mathrm{B}$ & \\
\hline $\mathrm{CO}_{2}$ & $219.6 \pm 54.8$ & $257.1 \pm 95.9$ & & $199.3 \pm 52.3 \mathrm{~A}$ & $262.7 \pm 63.1 \uparrow \mathrm{A}$ & $307.3 \pm 92.8 \uparrow$ \\
\hline \multicolumn{7}{|l|}{ Renal } \\
\hline $\mathrm{S}$ & $344.0 \pm 24.5$ & & & $165.3 \pm 40.7 \mathrm{~A}$ & $109.3 \pm 61.4 \downarrow \mathrm{B}$ & $125.5 \pm 67.9 \downarrow$ \\
\hline NS & $282.4 \pm 55.1$ & & & $78.1 \pm 29.0 \downarrow \mathrm{B}$ & $17.9 \pm 27.2 \downarrow \mathrm{A}$ & \\
\hline NS & $298.1 \pm 79.1$ & & & $298.3 \pm 73.5$ & $205.1 \pm 156.3 \mathrm{~B}$ & \\
\hline $\mathrm{CO}_{2}$ & $326.7 \pm 134.5$ & $258.4 \pm 102.4$ & & $361.4 \pm 231.51$ & $346.4 \pm 109.5$ & $409.7 \pm 12.87 \uparrow \mathrm{B}$ \\
\hline \multicolumn{7}{|l|}{ Muscle } \\
\hline $\mathrm{S}$ & $14.7 \pm 2.1$ & & , & 2.38 & $4.7 \pm 2.0$ & $5.2 \pm 2.35 \downarrow \mathrm{A}$ \\
\hline NS & $11.4 \pm 2.9$ & & & $3.6 \pm 1.6 \downarrow$ & $1.3 \pm 0.6 \downarrow$ & 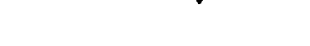 \\
\hline $\mathrm{CO}_{2}$ & $10.5 \pm 3.4$ & $9.2 \pm 4.1$ & & $4.5 \pm 4.1 \downarrow$ & $1.9 \pm 1.5 \downarrow$ & $3.1 \pm 1.8 \mathrm{~B}$ \\
\hline
\end{tabular}

'Values are mean \pm S.D.

${ }^{2}$ Definitions: $\uparrow$, mean value significantly greater than baseline value for that group $(P<0.05)$; $\downarrow$, mean value significantly lower than baseline value for that group $(P<0.05)$; A, B or A, B, B: group A is significantly different from group B (or from both other groups, B, B) at that point in the study $(P<0.05) ; \mathrm{S}$, room air breathing survivors; NS, room air breathing non-survivors; and $\mathrm{CO}_{2}, \mathrm{CO}_{2}$ breathing animals.

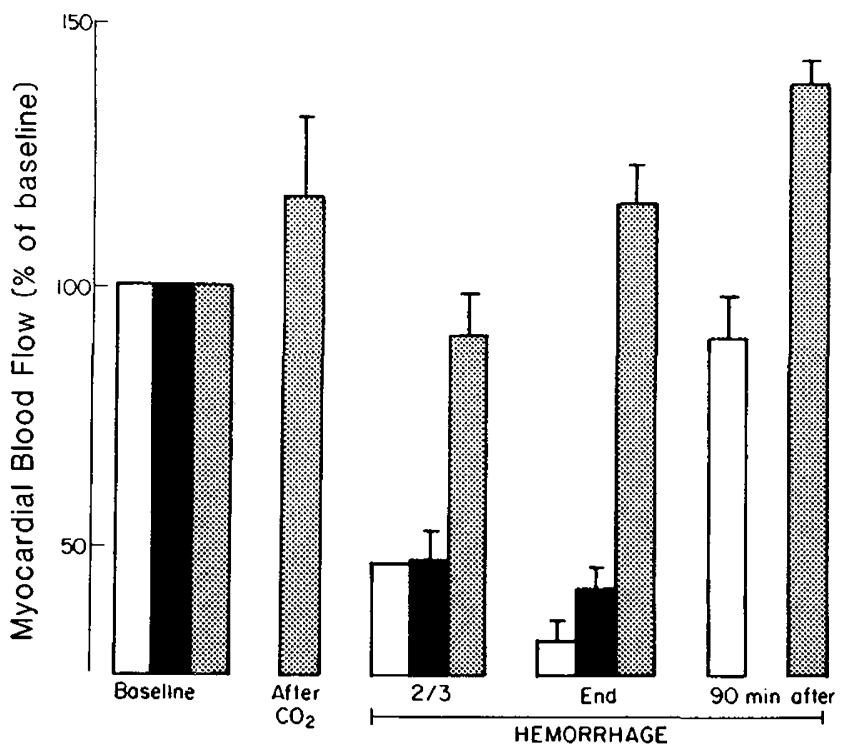

Fig. 1. Myocardial blood flow before, during and after hemorrhage in the three groups of lambs. Values are expressed as \% of the baseline measurement. Symbols for the three groups are white bars, room air breathing survivors; black bars, room air breathing non-survivors; and shaded bars, the $\mathrm{CO}_{2}$ breathing animals. Values are mean plus 1 S.E. of the mean.

orrhage. In every set of measurements in all three groups, the percentage decrease in total proteins was less than that of Hct.

Organ blood flow. Table 3 shows the changes in organ blood flow expressed as flow per $100 \mathrm{~g}$ of tissue.

Flow to muscle and kidneys fell in all three groups. Renal flow was lower in the room-air non-survivors than in the other groups at two-thirds and end-hemorrhage. Muscle flow was lower in the $\mathrm{CO}_{2}$ group than in the room-air survivors at $90 \mathrm{~min}$ posthemor- rhage. Adrenal flow varied widely, but the only significant changes were at 90 min posthemorrhage when it had more than doubled in the room-air survivors but increased by only $25 \%$ in the $\mathrm{CO}_{2}$ group. It did not change in the non-survivors.

There were major differences between groups in myocardial and brain flow. These are illustrated in Figures 1 and 2 as well as Table 3. Myocardial blood flow in the room-air lamb group decreased markedly during hemorrhage and paralleled the decreases in blood pressure and heart rate. In the survivors, it rose with heart rate and blood pressure after the end of hemorrhage and approached baseline by $90 \mathrm{~min}$ posthemorrhage. In the lambs
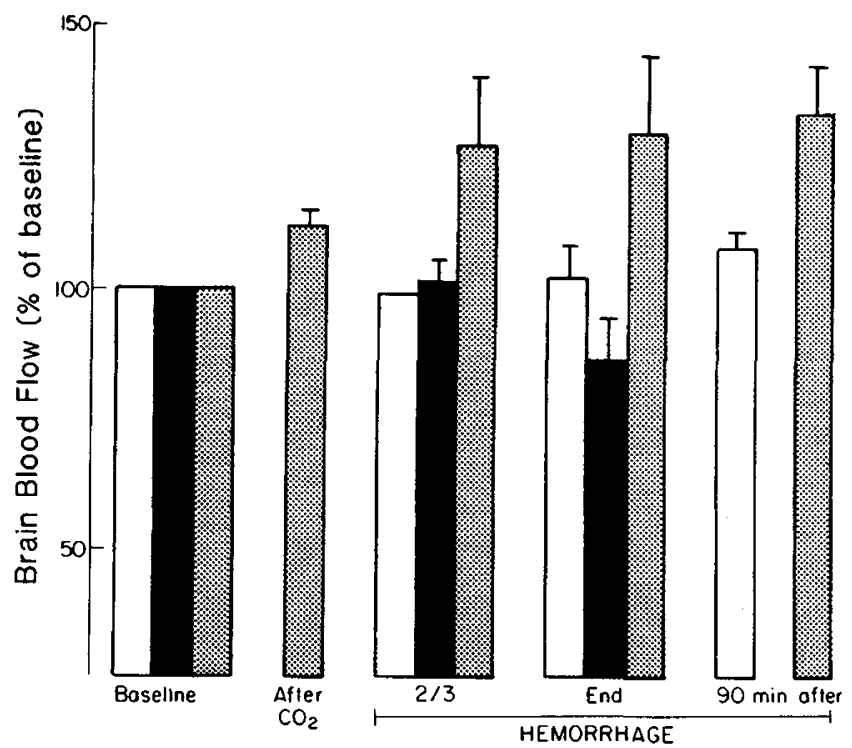

Fig. 2. Brain blood flow before, during, and after hemorrhage in the three groups of lambs. Flow is expressed as \% of the baseline measurement. Symbols for the three groups are the same as in Figure 1. 
that breathed $\mathrm{CO}_{2}$, myocardial blood flow decreased slightly but not significantly at two-thirds hemorrhage and increased significantly above baseline at the end of the hemorrhage and $90 \mathrm{~min}$ posthemorrhage. At two-thirds and the end of the hemorrhage, myocardial flow in the $\mathrm{CO}_{2}$ group was significantly higher than in the room-air groups.

The lambs in room air maintained baseline brain flow at twothirds of hemorrhage. At the end of the hemorrhage, when mean blood pressure averaged 23-25 torr in both room-air groups, the flow was reduced by almost $50 \%$ in the non-survivors, but was still unchanged from baseline in the survivors. By $90 \mathrm{~min}$ it rose slightly but not significantly in the survivors. In the lambs that breathed $4.5 \% \mathrm{CO}_{2}$ the brain flow was increased $13 \%$ after $15 \mathrm{~min}$ of breathing $\mathrm{CO}_{2}$, then continued to increase significantly during the hemorrhage, reaching $140 \%$ of baseline at end-hemorrhage and being nearly as high at $90 \mathrm{~min}$ posthemorrhage.

\section{DISCUSSION}

We have described an experimental model for hemorrhage in the newborn lamb in which $50 \%$ of the blood volume is removed by rapid hemorrhage and no shed blood or other fluid is replaced. No general anesthetic was used in order to avoid the effects of such agents in altering the normal homeostatic responses (10). One of the striking findings was the ability of many animals to withstand massive hemorrhage and survive for at least a short time. Eight of the 19 lambs breathing room air, and four of the five breathing $\mathrm{CO}_{2}$, survived.

Some responses were the same in the room air and the $\mathrm{CO}_{2}$ breathing animals and were to be expected based on past studies. All had a moderate hemodilution (26). All had a decrease in blood flow to the kidneys and skeletal muscle and a metabolic acidosis $(11,12,35)$. All had a fall in blood pressure and heart rate during the hemorrhage, but the $\mathrm{CO}_{2}$ breathing animals were less hypotensive and bradycardic. The hypotension was expected but the bradycardia is seemingly at variance with the expected change during hemorrhage $(2,6)$; however, several recent studies in both newborn and adult animals have pointed out that bradycardia does occur early in hemorrhage and hypotension $(3,14,33,35)$. This has also been observed in humans (36). The two major differences between the groups were in myocardial and cerebral blood flow. Cerebral blood flow was unchanged during hemorrhage in the room-air breathing animals that survived and decreased in those that died. On the other hand cerebral blood flow increased in the $\mathrm{CO}_{2}$-breathing animals. Myocardial blood flow fell with hypotension in the room-air breathing animals, whereas it gradually increased in the normocarbic animals. These differences in redistribution of blood flow may underlie the trend for increased survival in the $\mathrm{CO}_{2}$-breathing animals.

For the purpose of data analysis, we divided the room-air breathing lambs into two groups, survivors and non-survivors as did Rowe and Arcilla (33). Cardiovascular function declined continuously in the non-survivors, whereas in the survivors it declined initially but was improving by the end of the study. We do not known whether the survivors would have continued to improve and survive for another 12 or $24 \mathrm{~h}$; however, the differences were great enough that the division into two groups seems more appropriate than combining them into a single group for analysis. We wanted to study the responses to an extreme hemorrhage that was marginally compatible with survival. The experimental protocol achieved this because just $40 \%$ of the room-air breathing lambs survived. Under these conditions, the slightly higher blood volume hemorrhaged in the non-survivors may have determined their outcome. The somewhat smaller volume hemorrhaged in the survivors may be the limit to which the hyperventilating, hypocarbic lamb can adapt. This would be consistent with the lower blood pressure and earlier nadir of the bradycardia in the non-survivors. The differences in brain and myocardial flow would then follow. There were no other features that distinguished survivors from non-survivors with the possible exception of $\mathrm{PaO}_{2}$.
Of course the difference in survival may have been due to a variation in biologic factors that we did not measure.

$\mathrm{PaO}_{2}$ rose throughout the study period in both the room air survivors and the $\mathrm{CO}_{2}$-breathing animals. In the room-air nonsurvivors, $\mathrm{PaO}_{2}$ did not change although they were also hypocarbic. This suggests that there was poorer matching of ventilation and perfusion with a small increase in intrapulmonary shunting in them. On the average the lower $\mathrm{PaO}_{2}$ in this group was not physiologically significant in terms of oxygen content because the values were still in a range that would assure $90-95 \%$ saturation; however, from the end of the hemorrhage onward, there was a large variation and therefore some of these animals were significantly desaturated.

In our studies, brain blood flow fell in the non-survivors. This is similar to changes seen by others in the late phases of shock (20, 32). In the room-air survivors, brain flow remained constant during hemorrhage when they were hypotensive. This means that there must have been cerebral-vascular vasodilatation; however, hemoglobin and therefore oxygen-carrying capacity and arterial oxygen content were falling during the hemorrhage. If there had been optimal regulation of cerebral blood flow there would have been even further vasodilatation to increase brain blood flow proportional to the drop in arterial oxygen content in order to maintain oxygen delivery $(13,18)$.

We calculated oxygen delivery to the brain $\left(\mathrm{ml} \mathrm{O} \mathrm{O}_{2}\right.$ delivered per $100 \mathrm{~g}$ tissue per min) from the product of arterial blood oxygen content and brain blood flow. Figure 3 shows the findings in the three groups of lambs. During the hemorrhage oxygen delivery declined in both room-air groups. It was significantly below baseline in the non-survivors at two-thirds hemorrhage and in both survivors and nonsurvivors by the end of the hemorrhage. Oxygen delivery increased somewhat in the survivors by $90 \mathrm{~min}$ posthemorrhage, but was still significantly below baseline. In the $\mathrm{CO}_{2}$-breathing animals there was a small, but significant, increase in oxygen delivery from baseline after $15 \mathrm{~min}$ breathing $\mathrm{CO}_{2}$. This coincided with the transient rise in $\mathrm{PaCO}_{2}$ at that time. Thereafter, during the hemorrhage and recovery period, $\mathrm{O}_{2}$ delivery was not significantly different from baseline. Oxygen delivery in the roomair breathing groups was significantly lower than in the $\mathrm{CO}_{2}$ breathing group at endhemorrhage and $90 \mathrm{~min}$ posthemorrhage.

Hypocarbia is known to produce acute hypotension (8) and the room-air survivors had lower blood pressures at two-thirds and endhemorrhage; thus, they would have had to vasodilate more than the $\mathrm{CO}_{2}$ animals in order to achieve a comparable increase in brain blood flow and to maintain $\mathrm{O}_{2}$ delivery. It could be argued that during the hemorrhage the room-air breathing animals were maximally vasodilated at endhemorrhage in response to the more severe hypotension and therefore could not vasodilate any further. During the post-hemorrhage period when the blood pressures in the two groups were comparable, brain blood flow and
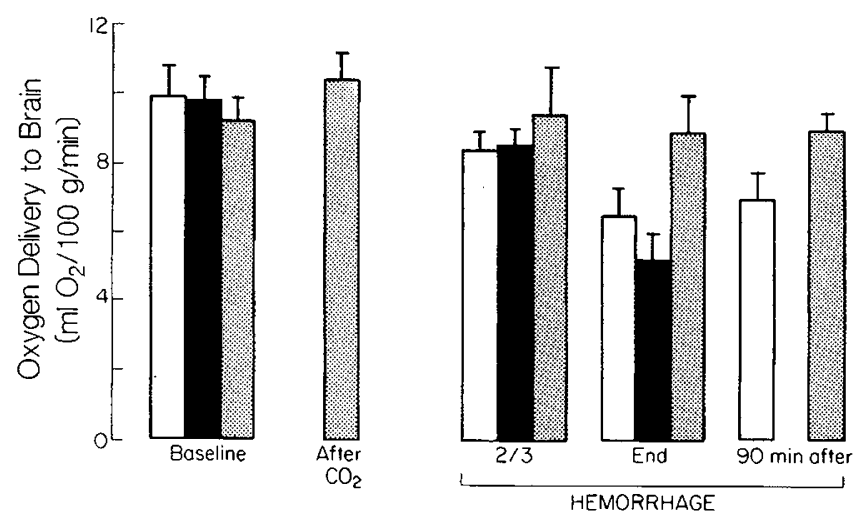

Fig. 3. Oxygen delivery before, during, and after hemorrhage in the three groups of lambs. Cerebral oxygen delivery is in $\mathrm{ml}$ of $\mathrm{O}_{2}$ per $100 \mathrm{~g}$ tissue per min. Symbols are the same as in Figures 1 and 2. 
$\mathrm{O}_{2}$ delivery were still higher in the $\mathrm{CO}_{2}$ group than in the roomair survivors.

$\mathrm{PaCO}_{2}$ has a major effect on cerebral-vascular resistance; flow increases with hypercarbia and decreases with hypocarbia $(15,34)$; however, previous studies have shown that this effect is reduced or obliterated in the face of hypotension or circulatory failure (15, 30). In our room-air breathing animals there was what Mchedlishvili (24) has called an antagonistic relationship between regulators of brain blood flow with hypotension and anemia tending to vasodilate and hypocarbia to vasoconstrict. In these conditions hypocarbia still reduce brain blood flow significantly when compared to normocarbia.

Myocardial blood flow in the room-air breathing animals fell during hemorrhage and in the survivors rose back towards baseline levels. These changes closely paralleled the changes in heart rate and systemic blood pressure and presumably paralleled the changes in myocardial work. The reduction in myocardial work was less during hemorrhage in the $\mathrm{CO}_{2}$-breathing group because blood pressure fell less than in the room-air groups. Myocardial flow in them did not fall along with blood pressure during hemorrhage. In the recovery period, when their blood pressure was similar to that of the room-air survivors, their myocardial flow rose above baseline. Jan et al. (17) recently showed that the combination of anemia and hypotension resulted in an increase in coronary blood flow, which tended to maintain a constant oxygen delivery to the heart. Our $\mathrm{CO}_{2}$-breathing lambs had the same type of response, whereas neither the room-air survivors or non-survivors did. Case et al. (5) and Koehler et al. (19) have shown that $\mathrm{CO}_{2}$ changes coronary vascular resistance in the same direction as it does cerebral vascular resistance. Our data suggest that in the myocardium as in the brain, hypocarbia has an adverse effect on the adaptive responses to hypotension and anemia.

Preventing hypocarbia appears to increase the lamb's ability to adapt successfully to hemorrhage. Blood flow and oxygen delivery to the brain and myocardium are higher in the $\mathrm{CO}_{2}$-breathing than in the room-air breathing animals. This may be partly due to the higher systemic blood pressures in the normocarbic animals but part appears to be due to greater vasodilation of these vascular beds. Our data do not indicate whether these differences are due to direct local effects of $\mathrm{CO}_{2}$ or are mediated through changes in vasoactive hormones or through reflexes. The studies of Koehler and Cowards in unanesthetized adult dogs suggest that the effects of $\mathrm{CO}_{2}$ on systemic vascular resistance and blood pressure may be a reflex whereas its effect on myocardial flow is a local direct effect of $\mathrm{CO}_{2}$ (19).

Our findings suggest that hypocarbia may significantly alter the adaptive responses of the newborn to hemorrhage and shock. This is not a new concept. In 1922, Dale and Evals (8) introduced a paper, "Effects on the Circulation of Changes in the Carbon Dioxide Content of the Blood." with the statement, "Recent years have produced much discussion of the phenomena of acapnia and their possible relation to conditions of shock." Sudden massive hemorrhage occurs in the newborn around the time of birth. Most of these infants have also suffered intrapartum asphyxia and require assisted ventilation for resuscitation (28). In our experience such ventilatory resuscitation often leads to temporary hypocarbia during the first $\mathrm{h}$ after birth. The cerebral blood flow of the newborn infant is at least as sensitive to changes in $\mathrm{PaCO}_{2}$ as is that of the adult man $(21,31)$.

If the human newborn's circulatory responses to hemorrhage are similar to those we have observed in lambs, it might be important to carefully control assisted ventilation in order to maintain $\mathrm{PaCO}_{2}$ in the normal range. There are several noteworthy differences between the conditions of our studies and the clinical situation. Our lambs were not hypoxic before or during the study, whereas the newborn who has suffered asphyxia and hemorrhagic shock has been hypoxic and this could alter the homeostatic responses. Also, our lambs were term newborns, whereas many infants who suffer hemorrhage are born prematurely $(9,27,28)$ and vascular homeostatic responses may differ in the preterm infant. Furthermore, the preterm infant is at risk for germinal matrix hemorrhage and one could speculate that maintaining normocarbia during hemorrhage could either increase or decrease the risk of such a hemorrhage through the effects on cerebral blood flow and oxygen delivery.

\section{REFERENCES AND NOTES}

1. Barr, P. A., Bailey, P. E., Sumners, J., and Cassidy, G.: Relation between arterial blood pressure and blood volume and effect of infused albumin in sick preterm infants. Pediatrics, 60: 282 (1977).

2. Brinkman, C. R. III, Moffid, M., and Assali, N. S.: Circulatory shock in pregnant sheep, III. effects of hemorrhage on uteroplacental and fetal circulation and oxygenation. Am. J. Obstet. Gynecol., 118: 117 (1974).

3. Bronshvag, M. M.: Cerebral pathophysiology in hemorrhagic shock, nuclide scan data, fluorescence microscopy and anatomic correlation. Stroke, 11: 50 (1980).

4. Brown, E. G., Krauskop, R. W., McDonnell, F. E., and Sweet, A. Y.: Blood volume and blood pressure in infants with respiratory distress. J. Pediatr. 87 : $1133(1975)$.

5. Case, R. B., Felix, A., Wachter, M., Kyriakidis, G., and Castellana, F.: Relative effect of $\mathrm{CO}_{2}$ on canine coronary vascular resistance. Circ. Res., 42: 410 (1979).

6. Chien, S.: Role of sympathetic nervous system in hemorrhage. Physiol, Rev., 47: 214 (1967).

7. Clayton, E. M., Pryor, J. A., Wierdsma, J. G., and Whitacre, F. E.: Fetal and maternal components in third-trimester obstetric hemorrhage. Obstet. Gynecol., 24: 56 (1964).

8. Dale, H. H. and Evans, C. L.: Effects on the circulation changes in the carbon dioxide content of the blood. J. Physiol., 56: 125 (1922).

9. Faxeluis, G., Raye, V., Gutberbt, R., Tsiantos, A., Dolanski, E., Dehan, M., Dyer, N., Lindstrom, D., Brill, A. B., and Stahlman, M.: Red cell volume measurements and acute blood loss in high risk newborn infants. J. Pediatr., 90: 272 (1977).

10. Forsyth, R. P. and Hoffbrand, B. I.: Redistribution of cardiac output after sodium pentobarbital anesthesia in the monkey. Amer. J. Physiol., 218: 214 (1970)

11. Forsyth, R. P., Hoffbrand, B. I., and Melmon, K. L.: Redistribution of cardiac output during hemorrhage in the unanesthetized monkey. Circ. Res., 27: 311 (1970).

12. Getzen, L. C., Pollack, E. W. and Wolfman, E. F.: Serum protein concentration during hemorrhagic shock. Surg. Gynecol. Obst., 144: 42 (1977).

13. Haggendal, E., Nilsson, N. J., and Norback, B.: Effects of blood corpuscle concentration on cerebral blood flow. Acta Chir. Scand., Suppl., 364: 3 (1966).

14. Hallamnn, G., Urban, A. E., Schmidt, H. D., et al.: Experimental studies of peculiar pathophysiological physiology of shock in early infancy. Ann. Cirg. Infant, 13: 123 (1972).

15. Harper, A. M. and Glass, H. E.: Effect of alterations in arterial carbon dioxide tension on the blood flow through the cerebral cortex at normal and low arterial blood pressures. J. Neurol. Neurosurg. Psychiat., 28: 449 (1965).

16. Heymann, M. A., Payne, B. D., Hoffman, J. I. E., and Rudolph, A. M.: Blood flow measurement with radionuclide-labeled microspheres. Prog. Cardiovasc. Dis., 20: 55 (1977).

17. Jan, K. M., Heldman, J. and Chien, S.: Coronary hemodynamics and oxygen utilization after hematocrit variations in hemorrhage. Am. J. Physiol., 239: H326 (1980).

18. Jones, M. D. Jr., Taystman, R. J., Simmons, M. A. and Molteni, R. A.: Effects of changes in arterial $\mathrm{O}_{2}$ content on cerebral blood flow in the lamb. Am. J. Physiol., H209 (1981).

19. Koehler, R. C., McDonald, B. W., and Krasney, J. A.: Influence of $\mathrm{CO}_{2}$ on cardiovascular response to hypoxia in conscious dogs. Am. J. Physiol., 239: H545 (1980).

20. Kovach, A. G. B. and Sandor, P.: Cerebral blood flow and brain function during hypotension and shock. Ann. Rev. Physiol., 38: 571 (1976).

21. Leahy, F. A. N., Cates, D., MacCallum, M. and Rigatto, H.: Effect of carbon dioxide and $100 \%$ oxygen on cerebral blood flow in preterm infants. J. Appl. Physiol., 48: 468 (1981)

22. Linderkamp, O., Versmold, H. T., Messow-Zahn, K., Muller-Holve, W., Riegel, K. P., and Betke, K.: The effect of intrapartum and intrauterine asphyxia on placental transfusion in premature and full-term infants. Eur. J. Pediatr., 127: 9l (1978).

23. Lister, G., Walter, T. K., Dallman, P. R. and Rudoph, A. M.: Oxygen delivery in lambs: cardiovascular and hematologic development. Am. J. Physiol., 237: H668 (1979).

24. Mchedlishvili, G.: Physiologic mechanism controlling cerebral blood flow. Stroke, 11: 240 (1980).

25. Miller, R. G.: Simultaneous statistical inference, p 81, (McGraw-Hill, New York, New York 1966).

26. Mott, J, C.: Hemorrhage as a test of the function of the cardiovascular system in rabbits of different ages. J. Physiol., 181: 728 (1965).

27. Phibbs, R. H., Clements, J. A., Creasy, R. K., Gregory, G. A., Kitterman, J. A., Schleuter, M. A., and Tooley, W. H.: Lung maturity, intrauterine growth, neonatal asphyxia and shock and the risk of hyaline membrane disease. Pediatr. Res., 10: 467 (1976)

28. Phibbs, R. H.: What is the evidence that blood pressure monitoring is useful in problems of neonatal intensive care units. J. F. Lucey, ed., 59th Ross Conference on Pediatric Research (1969).

29. Price, D. D., Swann, S. J., Hung, S. J., Kaufman, L., Huberty, J. P., and Shohet, 
S.: The measurement of circulating red cell volume using non-radioactive cesium and fluorescent excitation analysis. J. Lab. Clin. Med., 87: 535 (1976)

30. Purves, M. J. and James, I. M.: Observation on the control of cerebral blood flow on sheep fetus and newborn lamb. Circ. Res., 25: 651 (1969).

31. Rahilly, P. M.: Effects of $2 \%$ carbon dioxide, $0.5 \%$ carbon dioxide and $100 \%$ oxygen on cranial blood flow of the human neonate. Pediatrics, 66: 685 (1980)

32. Reivich, M., Kovach, A. G. B., Spitzer, J. J. and Sandor, P.: Cerebral blood flow and metabolism in hemorrhagic shock in baboons. In Neurohumoral and Metabolic Aspects of Injury, A. G. B. Kovach, ed., p. 19, (New York and London Plenum 1973).

33. Rowe, M. I. and Arcilia, R. A.: Hemodynamic adaptions of the newborn to hemorrhage. J. Pediatr. Surg., 3: 278 (1968)

34. Severinghaus, J. W. and Lassen, N.: Step hypocapnea to separate arterial from tissue $\mathrm{pCO}_{2}$ in the regulation of cerebral blood flow. Circ. Res., 20: 272 (1967).

35. Strodel, W. E., Callahan, M., Weintraub, W. H. and Coran, A. G.: The effect of various resuscitative regimens on hemorrhagic shock in puppies. J. Pediatr. Surg., 12: 809 (1977)

Copyright (C) 1983 International Pediatric Research Foundation, Inc. $0031-3998 / 83 / 1701-0070 \$ 02.00 / 0$
36. Wallace, J. and Sharpey-Schafer, E. P.: Blood changes following controlled hemorrhage in man. Lancet, 2: 393 (1941).

37. Wolf, A. V., Fuller, J. B., Goldman, E. J. and Mahoney, T. D.: New refractometric methods of the determination of total proteins in serum and in urine. Clin. Chem., 8: 158 (1962).

38. The authors are grateful to Bruce $\mathrm{D}$. Payne for assistance with $\mathrm{CsCl}$ blood volume and microsphere methodology and to Cynthia $\mathrm{L}$. Brown and Mark S. Marin for expert technical assistance with the studies. Richard Juster, Ph.D provided valuable assistance with the statistical analysis.

39. Requests for reprints should be addressed to: Dr. Roderic H. Phibbs, M.D Department of Pediatrics, Cardiovascular Research Institute, University of California-San Francisco, San Francisco, CA 94143.

40. This research was supported by Pediatric Pulmonary SCOR Grant HL-19185 Neonatal/Perinatal Training Grant HD-00397 Neonatal/Perinatal Training Grant HD-07162 CVRI Puimonary Training Grant HL-07185.

41. Received for publication September 4, 1981

42. Accepted for publication May 3, 1982. 